\title{
Campur Kode Bahasa Buton Terhadap Bahasa Indonesia Pada Rapat Organisasi Himpunan Mahasiswa Buton di Kota Samarinda
}

\author{
Samiun Samiun, Mursalim Mursalim, M. Rusydi Ahmad \\ Universitas Mulawarman \\ Universitas Mulawarman \\ Universitas Mulawarman \\ Email: samiunjakaria9@gmail.com
}

\begin{abstract}
The purpose of this study was to describe the form and factors causing code mixing at the Buton Student Association Organization Meeting in the city of Samarinda. This research uses the matching and agih method. The data collection technique used the listening method and the speaking method. The results of the study show the form of code mixing between Butonese and Indonesian at the Buton Student Association Organization Meeting in the city of Samarinda and the factors that cause code mixing. The forms of Code Mixing are 1) Code Mixing in the form of words, 2) Code Mixing in the form of phrases, 3) Code Mixing in the form of clauses. There are 2 factors that cause code mixing, namely 1) the speaker factor, 2) the language factor. From the results of this study, it can be concluded that the communication process that occurs at the Buton Student Association Organization Meeting in the city of Samarinda is in the form of code mixing in the form of words, phrases and clauses. Factors causing code mixing are speaker factors and language factors.
\end{abstract}

Keywords: code mixing, butonese language

\section{PENDAHULUAN}

Bahasa sebagai alat komunikasi dan interaksi yang dimiliki oleh manusia memegang peranan penting dalam kehidupan sehari-hari. Tanpa penggunaan bahasa, dipastikan segala kegiatan manusia akan lumpuh. Hal inilah yang menjadikan bahasa sebagai alat komunikasi yang paling efektif bagi manusia. Satu hal yang tidak dapat dipungkiri ialah dari implementasi bahasa sebagai alat komunikasi dalam masyarakat akan terjadi kontak bahasa. Kontak bahasa yang dimaksud disini ialah penggunaan dua bahasa atau lebih dalam suatu proses komunikasi sosial.
Dalam suatu masyarakat, manusia tidak mungkin dapat berkomunikasi apabila anggota masyarakat tersebut tidak menggunakan bahasa sebagai media atau sarananya. Manusia bukanlah makhluk individu, melainkan makhluk sosial yang didalam kesehariannya membutuhkan yang namanya bahasa.

Dalam kenyataannya, manusia selalu melakukan kegiatan komunikasi dari satu orang kepada orang lain dengan bahasa yang bervariasi. Hal ini bertujuan untuk mendapatkan informasi dan selalu berusaha mencari sesuatu yang 
dibutuhkan. Seperti halnya masyarakat yang berkomunikasi dalam bidang ekonomi, budaya, agama, dan bidang. sosial lainnya. Dengan adanya komunikasi dari satu masyarakat ke masyarakat lain maka akan tercipta kemampuan berbahasa yang beraneka ragam.

Keragaman bahasa yang terjadi di msyarakat menyebabkan terciptanya masyarakat bilingual atau multilingual yang memiliki dua bahasa atau lebih sehingga mereka harus memilih bahasa atau variasi bahasa mana yang harus digunakan dalam sebuah situasi. Penguasaan terhadap lebih dari satu bahasa oleh seseorang mengakibatkan kedwibahasaan dalam komunikasi.

Pada situasi kedwibahasaan akibat yang ditimbulkan adalah peristiwa alih kode dan campur kode. Alih kode ialah peristiwa penggantian bahasa atau ragam bahasa oleh penutur karena adanya sebab-sebab tertentu yang dilakukan dengan sadar (Chaer dan Agustina, 2010 : 107). Kontak yang terjadi secara terusmenerus antara dua bahasa atau lebih akan mengakibatkan gejala kebahasaan yang disebut campur kode.

Selain dalam penggunaan bahasa seharihari, penggunaan bahasa Indonesia yang baik juga harus digunakan dalam komunikasi rapat. Bahasa yang digunakan dalam rapat pada dasarnya menggunakan bahasa resmi yaitu bahasa Indonesia, tetapi tidak menutup kemungkinan bahasa Indonesia yang digunakan terjadi variasivariasi bahasa campur kode. Peristiwa campur kode sangat mungkin terjadi dalam kegiatan rapat Organisasi Himpunan Mahasiswa Buton di kota Samarinda karena dalam rapat dihadiri oleh bebrbagai partisipan yang mempunyai tingkat kemampuan berbahasa dan latar belakang yang berbeda.

Bahasa Buton adalah salah satu bahasa daerah yang ada di kota Samarinda, yang digunakan oleh suku asli Buton sebagai alat komunikasi dalam berinteraksi antara anggota masyarakat Buton yang ada di kota Samarinda dari latar belakang yang berbeda-beda.

Rapat merupakan pertemuan atau berkumpulnya minimal dua orang atau lebih untuk memutuskan suatu tujuan. Rapat juga dapat diartikan sebagai media komunikasi kelompok yang bersifat tatatp muka yang sering diselenggarakan atau dilakukan oleh banyak organisasi baik itu swasta ataupun pemerintahan. Rapat dalam organisasi biasanya di pimpin oleh ketua atau yang mempunyai jabatan tertinggi dan diikuti oleh anggota-anggota.

Selain kesalahan campur kode yang dilakukan di kehidupan sehari-hari, kesalahan campur kode juga sering terjadi di sebuah situasi formal seperti pada kegiatan rapat. Berkaitan dengan kesalahan campur kode yang terjadi pada kegiatan rapat, peneliti tertarik untuk melakukan penelitian pada Rapat Organisasi Himpunan Mahasiswa Buton di kota Samarinda. Hal ini dilakukan karena dalam kegiatan rapat harusnya menggunakan bahasa yang formal dan bersifat ilmiah.

Penelitian ini dilakukan dengan mengacu kepada dua alas an utama. Pertama, peneliti ingin melakukan penelitian dalam bidang kebahasaan, khususnya mengenai campur kode. Kedua, peneliti ingin melakukan pengkajian lebih dalam mengenai campur kode pada rapat Organisasi Himpunan Mahasiswa Buton di kota Samarinda dan apa yang melatarbelakangi terjadinya campur kode tersebut. Peneliti ini dilakukan karena peneliti ingin berusaha menghadirkan campur kode tersebut kedalam data tertulis, sehingga kita menjadi yakin bahwa pengkajian campur kode dapat dilakukan dengan berdasarkan teori yang ada.

Adapun permasalahan yang menjadi kajian dalam penelitian ini yaitu, bagaimana bentuk campur kode pada rapat Organisasi Himpunan Mahasiswa Buton di kota Samarinda dan apa yang melatarbelakangi terjadinya campur kode tersebut.

Tujuan penelitian ini adalah mendeskripsikan bentuk campur kode pada rapat Organisasi Himpunan Mahasiswa Buton di kota Samarinda dan apa yang melatarbelakangi terjadinya campur kode tersebut.

Penelitian ini secara teoritis diharapkan dapat memberikan manfaat untuk memperkaya referensi dibidang kebahasaan dan memeberikan masukan bagi pengembang kajian di bidang sosiolinguistik, khususnya pada kajian campur kode dan Manfaat penelitian ini secara praktis diharapkan dapat memberi alternative media pembelajaran dan bahasa Indonesia, serta memberikan pengetahuan kepada penulis mengenai deskripsi campur kode.

Fisham (Chaer dan Agustina, 2010 : 3) mengatakan bahwa sosiolinguistik adalah kajian tentang ciri khas variasi bahasa, fungsi-fungsi variasi bahasa, dan pemakai bahasa karena ketiga 
unsur ini selalu berinteraksi, berubah, dan saling mengubah satu sama lain dalam masyarakat tutur. Sedangkan, Menurut Wardhaugh, Holmes, Hudson (Malabar 2015 : 2) sosiolinguistik mengkaji hubungan bahasa dan masyarakat, yang mengaitkan dua bidang yang dapat dikaji secara terpisah, yaitu struktur formal bahasa oleh linguistic dan struktur masyarakat oleh sosiologi.

Peristiwa tutur adalah terjadinya atau berlangsungnya interaksi linguistic dalam satu bentuk ujaran atau lebih yang melibatkan dua pihak, yaitu penutur dan lawan tutur, dengan satu pokok tuturan, di dalam waktu, tempat dan situasi tertentu (Chaer dan Agustin 2010 : 47). Menurut Aslinda dan Leni (2007: 31) mengatakan bahwa peristiwa tutur merupakan terjadinya interaksi linguistik untk saling menyampaikan informasi antara dua belah pihak tentang suatu topic atau pokok pikiran, waktu dan tempat.

Pembicaraan mengenai alih kode biasanya diikuti dengan pembicaraan mengenai campur kode. Kedua peristiwa yang lazim terjadi dalam masyarakat yang bilingual ini mempunyai kesamaan yang besar, sehingga sering kali sukar dibedakan. Kesamaan yang ada antara alih kode dan campur kode adalah digunakannya dua bahasa atau lebih atau dua varian dari sebuah bahasa dalam satu masyarakat tutur.

Thelander (Chaer dan Agustina, 2010 : 115) menjelaskan bila didalam suatu peristiwa tutur, klausa dan frase campuran dan masingmasing klausa atau frase itu tidak lagi mendukung fungsi sendiri-sendiri, maka peristiwa yang terjadi adalah campur kode.

Campur kode terjadi apabila seorang penutur bahasa, misalnya bahasa Indonesia memasukkan unsur-unsur bahaa daerahnya ke dalam pembicaraan bahasa Indonesia. Dengan kata lain, sesorang yang berbicara dengan kode utama bahasa Indonesia yang memiliki fungsi keotonomiannya, sedangkan kode bahasa daerah yang terlibat dalam kode utama merupakan serpihan-serpihan saja fungsi atau keotonomian sebagai sebuah kode (Aslinda dan Leni, 2007:87).

Berdasarkan unsur-unsur kebahasaan yang terlibat di dalamnya, campur kode dapat dibedakan berdasarkan wujud campur kodenya, suwito (Rokhman, 2013:45) yaitu berupa kata, frasa dan klausa.

1. Kata adalah morfem atau kombinasi morfem yang oleh bahasawan dianggap sebagai satuan terkecil yang dapat diujarkan sebagai bentuk yang bebas (Kridalaksana, 2008:110).

2. Frasa adalah gabungan dua kata atau lebih yang sifatnya tidak prediktif (Kridalaksana, 2008:66). Menurut Ramlan (2005:138) frasa adalah satuan gramatik yang terdiri dari dua kata atau lebih yang tidak melampaui batas fungsi unsur klausa.

3. Klausa adalah satuan gramatikal berupa kelompok kata yang sekurang-kurangnya terdiri dari subejk dan predikat, dan mempunyai potensi untuk menjadi kalimat (Kridalaksana, 2008:124).

Menurut Suwito (dalam Suandi, 2014 : 142) Latar belakang terjadinya campur kode dapat digolongkan menjadi dua seperti berikut :

\section{A. Latar Belakang Sikap Penutur}

Latar belakang penutur ini berhubungan dengan karakter penutur, seperti latar sosial, tingkat pendidikan., atau rasa keagamaan. Misalnya, penutur yang memiliki latar belakang sosial yang sama dengan mitra tuturnya dapat melakukan campur kode etik berkomunikasi. Hal ini dapat dilakukan agar suasana pembicaraan menjadi akrab.

\section{B. Kebahasaan}

Latar belakang kebahasaan atau kemampuan berbahasa juga menjadi penyebab seseorang melakukan campur kode, baik penutur maupun orang yang menjadi pendengar atau mitra tuturnya. Selain itu, keinginan untuk menjelaskan maksud atau menafsirkan sesuatu juga dapat menjadi salah satu faktor yang ikut melatarbelakangi penutur melakukan campur kode.

Jenis penelitian yang digunakan dalam penelitian ini adalah penelitian kualitatif. Menurut Taylor (Muhammad 2014:30) mendefinisikan Metodelogi kualitatif sebagai prosedur penelitian yang menghasilkan data deskriptif berupa katakata tertulis atau lisan dari orang-orang dan perilaku yang dapat diamati.Dalam penelitian ini teknik pengum pulan data peneliti menggunakan dua metode yaitu metode simak dan metode cakap. 


\section{PENYAJIAN DATA DAN PEMBAHASAN}

\section{Analisis Bentuk Campur Kode}

A. Bentuk Kata

\section{DATA 1}

1) M : karena, toaru yang memilih Ruslan maka yang menjadi ketua panitia

Ruslan

2) AG 1 : Saran moderator, cuke'e tersisa 2 nama langsung di voting saja siapa

dan sekretaris

yang menjadi bendahara

3) AG 3 : Sepakat langsung divoting saja

1. Toaru (Banyak)

Pada data diatas terdapat bentuk campur kode berupa kata bahasa Buton yang menyisip ke dalam bahasa Indonesia. Hal tersebut dapat dibuktikan pada kata 'Toaru' yang memiliki arti 'Banyak'. Kata 'banyak' merupakan satuan bahasa terkecil yang dapat berdiri sendiri dan merupakan satuan terkecil dalam bahasa yang memiliki arti atau makna yang belum mengalami proses pembentukan kata. Sehingga dengan adanya penyisipan kata tersebut menimbulkan adanya campur kode berupa kata.

\section{Cuke'e (itu)}

Pada analisis data 2 percakaan 8 terdapat bentuk campur kode berupa kata bahasa Buton yang menyisip kedalam bahasa Indonesia. Hal tersebut dapat dibuktikan pada kata 'Cuke'e' yang memiliki arti itu 'itu'. Kata 'itu' merupakan satuan bahasa terkecil yang belum mengalami proses pembentukan kata. Sehingga dengan adanya penyisipan kata tersebut menimbulkan adanya campur kode berupa kata.

\section{B. Bentuk Frasa}

\section{DATA 2}

4) M : Ada lagi saran dan tanggapan ane ciadane'e kita lanjut ke divisi

\section{humdan}

5) KP : Laporan dari humdan proposal yang belum diantar ada 3 terkhusus

alumni, untuk pengurus demisioner sudah dikomunikasikan dengan sekretaris.

6) M : bagaimana teman-teman ada saran dan tanggapan?

7) AG 9 : Saran untuk humdan memberitahu sekretaris untuk masimba

pakanae surat undangan

1. Ane ciadane'e

Ane ciadane'e yang memiliki arti 'jika tidak ada' dalam bahasa Indonesia termasuk ke dalam frasa karena adanya kata ' jika dan tidak ada' karena kata tersebut termasuk kedalam frasa adjektiva, yaitu frasa yang memiliki inti berupa kata sifat dalam unsur pembentuknya dengan menambahkan kata lain yang berfungsi menerangkan. Dengan adanya penyisipan frasa tersebut menimbulkan adanya campur kode.

2. Masimba pakanae'e

Masimba pakana'e yang memiliki arti 'segera dibuat' dalam bahasa Indonesia termasuk ke dalam frasa karena adanya kata ' segera dan dibuat' karena kata tersebut termasuk kedalam frasa adjektiva, yaitu frasa yang memiliki inti berupa kata sifat dalam unsur pembentuknya dengan menambahkan kata lain yang berfungsi menerangkan. Dengan adanya penyisipan frasa tersebut menimbulkan adanya campur kode. 


\section{Bentuk Klausa}

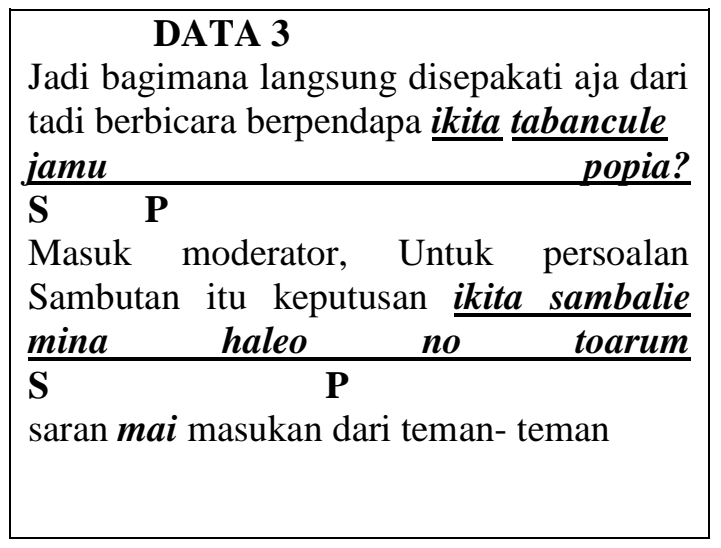

Dari percakapan di atas ditemukan campur kode bentuk klausa, yang merupakan gabungan kata yang sekurang-kurangnya terdiri atas subjek dan predikat. Bentuk klausa dalam percakapan tersebut adalah ikita tabancule jamu popia? Yang memiliki arti dalam bahasa Indonesia kita pulang jam berapa, ikita sambalie mina haleo no toarum yang memiliki arti dalam bahasa Indonesia kita semua dari tadi sudah banyak.

2. Analisis Faktor Penyebab Campur Kode

\section{Latar belakang Sikap Penutur}

Latar belakang penutur berhubungan dengan karakter penutur. Seperti latar social dan pengaruh lingkungan.

a. Latar Sosial

Dari hasil wawancara ditemukan latar social responden yang memang merupakan suku asli Buton dan bahasa yang digunakannya sehari-hari juga menggunakan bahasa Buton. Hal inilah yang membuat resonden sering melakukan campur kode ketika sedang melakukan komunikasi.

b. Pengaruh Lingkungan

Dari hasil wawancara juga ditemukan responden yang didaerah tempat tinggalnya masih sangat kental berkomunikasi menggunakan bahasa Buton. Sehingga membuat responden sering melakukan campur kode.

\section{Faktor Kebahasaan}

Sesuai dengan data yang telah disajikan, yaitu berupa tuturan dalam Rapat Organisasi Himpunan Mahasiswa Buton di kota Samarinda., maka dapat ditemui factor penyebab campur kode berdasarkan kebahasaan, sebagai berikut. a. Berbicara Tentang Topik

Tertentu.

Faktor penyebab campur kode dalam Rapat Organisasi Himpunan Mahasiswa Buton di kota Samarinda berupa berbicara tentang topic tertentu, dapat dilihat pada tuturan di bawah ini.

1. "Jadi bagimana langsung disepakati aja dari tadi berbicara berpendapat ikita tabancule jamu popia?"

2. "Masuk moderator, Untuk persoalan Sambutan itu keputusan ikita sambalie mina haleo no toarum saran mai masukan dari teman-teman."

Tuturan diatas menunjukkan faktor penyebab campur kode berupa berbicara tentang topic tertentu. Terkadang orang lebih suka berbicara tentang topic tertentu ke dalam satu bahasa. Kadang-kadang pembicara merasa bebas dan lebih nyaman untuk mengungkapkan perasaan emosionalnya ke dalam bahasa sehariharinya. Berdasarkan tuturan-tuturan tersebut, penutur ingin menyampaikan tuturannya dengan lebih nyaman sehingga menggunakan bahasa sehari-hari yang mudah dimengerti lawan bicaranya.

b. Menjadi tegas tentang sesuatu

Faktor penyebab campur kode dalam Rapat Organisasi Himpunan Mahasiswa Buton di Kota Samarinda berupa menjadi tegas tentang sesuatu dapat dilihat pada tuturan di bawah ini.

1. "Saran untuk humdan memberitahu sekretaris untuk masimba pakanae surat undangan"

2. "Proposal yang belum dianatar masimba diantar"

Berdasarkan pada tuturan 1 penutur menegaskan untuk memberitahu kepada sekretaris agar segera membuat surat undangan dan proposal yang belum diantar umtuk segera diantar. pada tuturan menegaskan untuk segera membuat surat. 


\section{KESIMPULAN}

Berdasarkan hasil penelitian yang telah disajikan pada bab sebelumnya, peneliti menyimpulkan beberapa hal sebagai berikut.

1. Bentuk campur kode yang terjadi dalam proses komunikasi pada Rapat Organisasi Himpunan Mahasiswa Buton di Kota Samarinda yaitu berupa kata, frasa dan klausa.

2. Faktor Penyebab terjadinya campur kode dalam proses komunikasi pada Rapat Organisasi Himpunan Mahasiswa Buton di Kota Samarinda ada dua yaitu Faktor.

a. Faktor latar belakang penutur yang meliputi

- Nilai sosial penutur

- Pengaruh lingkungan

b. Faktor kebahasaan yang meliputi

- Berbicara tentang topic tertentu

- Menjadi tegas tentang sesuatu

\section{REFERENCES}

Anwar. (1983). Linguistik Umum. Jakarta: PT. Rineka Cipta

Aslinda, Leni Syafyahya. (2007). Pengantar Sosiolinguistik. Bandung: PT. Refika Aditama.

Chaer, Abdul. (2014). Linguistik Umum. Jakarta: PT. Rineka Cipta.

Chaer, Abdul dan Leoni Agustina. (2004). Sosiolinguistik. Jakarta : PT. Rineka Cipta

Chaer, Abdul dan Leoni Agustina. (2010). Sosiolinguistik: Perkenalan Awal. Jakarta: PT. Rineka Cipta.

Kridalaksana, Harimurti. (2008). Катиs Linguistik. Jakarta: PT. Gramedia Pustaka

Malabar, Sayama. (2015). Sosiolinguistik. Gorontalo: Ideas Publishing.

Margono (2004). Metodologi Penelitian Pendidikan. Jakarta : Rineka Cipta.

Muhammad. (2014). Metode Penelitian Bahasa. Yogyakarta: Ar- Ruzz Media.

Padmadewi, dkk. (2014). Sosiolinguistik. Yogyakarta: Graha Ilmu.

Ramlan. (2005). Ilmu Bahasa Indonesia: Sintaksis. Yogyakarta: C.V. Karyono.

Rokhman, Fathur. (2013). Sosiolinguistik: Suatu Pendekatan Pembelajaran Bahasa dalam 